\title{
REVIEW
}

\section{Chemical mediators in the central}

\section{nervous system}

\author{
P. K. LAHIRI \\ P. SEN \\ M.D. \\ M.D.
}

Department of Pharmacology, Maulana Azad Medical College, New Delhi

SINCE the early thirties of this century it has been known that chemical substances are involved in the transmission of impulses at the neuromuscular junction, in autonomic anglia and at autonomic effector endings. It was later shown that a number of chemical agents produce their actions in the body by interfering with the process of chemical transmission.

Loewi (1921) was the first to demonstrate that following stimulation of the vagus nerve to the heart, a specific chemical substance is released at the nerve endings. The vagus nerve to the heart was stimulated in the frog and the perfusate from the heart, when perfused through the heart of another frog, caused immediate cardiac arrest. Loewi termed this hypothetical chemical substance 'Vagustoff' and later identified it as acetylcholine. Release of a similar substance in the mammalian heart was demonstrated by Feldberg \& Krayer (1933). Dale, Feldberg \& Vogt (1936) later reported the release of acetylcholine at the neuromuscular junction following stimulation of motor nerves to skeletal muscle.

It is now well recognized that acetylcholine is liberated at parasympathetic nerve endings, autonomic ganglia and skeletal neuromuscular junctions. It is customary to divide the actions of acetylcholine into 'muscarinic' at the parasympathetic nerve endings and 'nicotinic' at the level of autonomic ganglia and at the skeletal neuromuscular junction, because these actions closely resemble those produced by the alkaloids muscarine and nicotine respectively.

Oliver \& Schafer (1895) demonstrated the presence of a chemical substance in extracts of the adrenal gland, and this was subsequently identified as adrenaline. A few years later, Elliot (1904) reported that adrenaline was the chemical transmitter at sympathetic nerve endings. It is now known that the suprarenal extract contains both adrenaline and its precursor noradrenaline. However, noradrenaline has been shown to be the principal transmitter at the sympathetic nerve endings. The actions of adrenaline are traditionally classified as $\alpha$ and $\beta$ depending on the nature of the receptor activated. Adrenaline produces both $\alpha$ and $\beta$ types of action and it is possible to block these effects selectively by $\alpha$ and $\beta$ blocking agents. Noradrenaline has predominantly $\alpha$ actions, whereas isopropyl noradrenaline has mostly $\beta$ adrenergic effects. Recently it has been proposed that acetylcholine is the prime transmitter at sympathetic nerve endings, but that it acts as a chemical mediator for the release of noradrenaline from peripheral storage sites (Burn, 1965).

The discovery of chemical mediation in the peripheral and autonomic nervous systems gave a lead in recent years in exploring the possibility of the existence of similar mechanisms in the central nervous system (CNS). But here the problem is more complicated, and beset with technical difficulties. The structural complexity of the neurons and their intermingled fibres, the difficulty in approaching them at specific sites in the CNS and the experimental intricacies in the reproduction of responses mimicking their normal physiological actions have added further complications to such studies. Nevertheless, some of these problems have been solved in the past few years.

The purpose of the present review is to highlight the recent advances made in establishing the role of various autopharmacological substances in neural transmission in the CNS. In this respect, the first consideration is to determine the criteria that should be fulfilled by a substance for its recognition as a chemical mediator There has been considerable discussion in this regard (Paton, 1958; Curtis, 1961 ; Gaddum, 1962), and different suggestions have been 
made from time to time. Recently, Salmoiraghi, Costa \& Bloom (1965) have laid down three major criteria :

(a) The substance and the appropriate enzyme system for its metabolism must be present at the proper location.

(b) If the suspected substance is a known chemical agent, then the latter should possess pharmacological actions similar to those of physiological stimulation on the post-synaptic membrane.

(c) The transmitter released from the nerve endings must be proved to be identical with the suspected substance.

With respect to the first criterion, recent studies with the electron microscope have helped in locating the exact site for storage of the suspected chemical transmitter and its release. This has been further supported by the results of some preliminary experiments in which different areas of brain were extracted and assayed for the presence of pharmacologically active substances (Robson \& Stacey, 1962).

Fractionation studies with the ultracentrifuge have also assisted in the localization of the active substances (Whittaker, 1959). This method has been improved further with the introduction of the density gradient techniques with the aid of which the fractions can be more effectively separated than was previously feasible. These fractions can be examined by the electron microscope and tested biochemically for the presence of the active substance. From such studies it has become apparent that the active substances are located in small spherical sacs near the synapse and these have been termed synaptic vesicles. The pinched-off nerve endings in centrifugal material known as synaptosomes contain the highest amount of non-diffusible amines (Whittaker, Michaelson \& Kirkland, 1964). The synaptosomes enclose the terminal axoplasm, synaptic vesicles and a few mitochondria, and contain substances such as acetylcholine, noradrenaline, 5-hydroxytryptamine (5-HT), histaamine, dopamine and substance $P$. Although glutamate and $\gamma$-amino butyric acid (GABA) are present in all fractions, they do not appear to be concentrated in the synaptosomes. However, absence of localization of a substance in synaptosomes would not exclude the possibility of its transmitter potentiality, since the possibility of these substances being lost during separation procedures cannot be excluded (Salmoiroghi et al., 1965). It has also been shown that enzymes necessary for the synthesis of various mediators may be associated with the vesicles. It has been suggested that these vesicles orginate from the
Golgi apparatus in the cytoplasm of the neuron and then are transplanted down the axoplasm to the nerve terminal (de Robertis, 1964 ; Sandborn, 1964).

The fluorescent histochemical technique developed by Hillarp and his co-workers in Scandinavia (Carlsson, Falck \& Hillarp, 1962 ; Carlsson et al., 1964) has also helped in the localization of active substances in the subcellular fractions. When tissue sections containing amines are exposed to formaldehyde vapour, fluorescent compounds are formed; these can then be examined microscopically for their exact localization in situ. Such studies have revealed an intense fluorescence at the synaptic sites, whereas the fluorescence in the cell itself is diffuse.

After release of the transmitter at the presynaptic membrane, it must diffuse across the synaptic cleft to reach its post-synaptic site of action. Thus its ultimate action will not only depend upon the structure of the synaptic cleft but also on the presence or absence of catabolizing enzymes.

With the help of advanced techniques it has been possible to fulfil the first criterion for a number of substances. The second criterion has been more difficult to accomplish, but with the technique of microelectrophoresis it has been possible in some instances. In this method, a solus tion of a suitable salt of the chemical substance is introduced by means of a fine glass-barref micropipette (outer diameter 1-3 $\mu$ ) at the desired site in the CNS by stereotactic manipulation. The salt in solution dissociates into pharmacologically active and inactive ions. The pharmacologically active ions are driven out at the implanted site by an electric current. A recording electrode is also incorporated in the barrel to allow impulses to be recorded (Curtis, 1965). With this technique it has been possible to identify the sites of action of several mediators in the CNS. Furthermore, studies with antagonistic drugs have helped in the classification of acetylcholine action into muscarinic and nicotinic, and that of adrenaline into $\alpha$ and $\beta$ types. A further method has been evolved by Feldberg \& Sherwood (1954) in which drugs are injected directly into the cerebral ventricles. Feldberg and his colleagues have studied the actions of a number of drugs administered by this route.

It has not been possible to meet the third criterion with any measure of adequacy so far because of the technical difficulties. However, MacIntosh \& Oborin (1953) succeeded in collecting samples and measuring the amount of acetylcholine which exuded out when a small glass capsule containing saline was placed on the cor- 
tex. Acetylcholine was also collected from the cerebrum by Gaddum (1961) by using a pushpull cannula consisting of two fine concentric tubes, the inner one being a steel cannula and the outer either a polyethylene or a steel needle. Locke solution, introduced down the inner tube, emerges through the outer tube carrying with it the active mediators.

So far, several chemical substances have been shown to play the role of chemical mediators in the CNS and the current evidence available regarding some of these mediators will now be examined, with special reference to their actions.

\section{Acetylcholine}

The evidence that acetylcholine is a chemical transmitter in the spinal cord is available in abundance. In an early experiment, Bulbring \& Burn (1941) perfused the lower half of the spinal cord with one circulation and the leg muscles with another; administration of acetylcholine to the blood perfusing the spinal cord led to twitching of the leg muscles. In similar experiments, injection of cholinesterase inhibitors produced an identical response.

With recent techniques it is now possible to demonstrate the action of acetylcholine at specific sites in the CNS. Curtis \& Eccles (1958) have shown that the Renshaw cells, which are located within the ventromedial aspect of the ventral horn, are readily excited by electrophoretically administered acetylcholine. Stimulation of the Renshaw cells by the anterior horn cells leads to the inhibition of the latter and the action induced by acetylcholine closely resembles synaptic stimulation. Both forms of stimulation are depressed by locally injected dihydro- $\beta$-erythroidin, tetraethylammonium and d-tubocurarine, and potentiated by anticholinesterase compounds (Curtis, 1965). The acetylcholine sensitivity of these cells resembles that of sympathetic ganglia. However, these cells differ in their responses to acetylcholine and acetyl- $\beta$-methylcholine. Dihydro- $\beta$-erythroidin blocks the action of the former only, whereas atropine blocks the action of the latter without abrogating the former. It is possible, therefore, that both nicotinic as well as muscarinic types of actions are present in the CNS (Curtis \& Ryall, 1964). Transmission at the motor neurons and at the interneurons is more complex in nature and at these sites seems to be insensitive to acetylcholine.

In the brain stem, acetylcholine stimulates $35 \%$ and inhibits $12 \%$ of the cells at a site within 3 $\mathrm{mm}$ from the midline (Bradley, Dhawan \& Wolstencroft, 1964). The inhibitory receptors are likely to be muscarinic in type, whereas excita- tory receptors have both muscarinic and nicotinic properties.

A number of cortical neurons concentrated in the deeper layers of the cortex can be excited with acetylcholine (Spehlmann, 1963). This action is antagonized by atropine, hyoscine and nicotine and it indicates that the receptors are endowed only with muscarinic properties. Release of acetylcholine in the cortex has been demonstrated recently by several investigators (MacIntosh \& Oborin, 1953 ; Mitchell, 1963; Szerb, 1963).

In the cerebellum, Purkinje cells are stimulated by acetylcholine (Phillis, 1965), and in the granular layer some cells have also been found to be excitable to iontophoretically applied acetylcholine (McCance \& Phillis, 1964). Thus it appears that mapping of various areas of the brain in terms of their response to various drugs administered iontophoretically offers considerable possibilities in understanding the underlying mechanisms of chemical mediation. This may also lead to major re-orientation of ideas regarding the physiology of transmission in the near future.

\section{Catecholamines}

High concentrations of catecholamines are present in the hypothalamus, and low amounts in the cerebral cortex, whereas the brain stem content is intermediate (Vogt, 1954). Noradrenaline and its precursor dopamine are present in the grey matter of the spinal cord. The majority of the neurons of the spinal cord have been reported to remain unaffected by iontophoretically applied catecholamines (Curtis \& Koizumi, 1961; Curtis, Phillis \& Watkins, 1961). However, the interneurons of the inhibitory reticulo-spinal pathways are excitable by dopamine (McLennan, 1963). For the brain stem neurons, noradrenaline exhibits a dual action, about $29 \%$ of the cells being excited and 19\% inhibited. There is an initial latent period in its action, and the effects often outlast the period of iontophoretic administration of the drug by 2-3 min (Bradley \& Wolstencroft, 1965). In the cerebral cortex, the effects of dopamine and other catecholamines are always depressant in nature (Krnjevic \& Phillis, 1963a). Blocking agents do not seem to affect such actions. Current evidence tends to show that the actions may be of $\beta$ type, but a firm assertion cannot be made at present.

\section{5-Hydroxytryptamine}

Amin, Crawford \& Gaddum (1954) have demonstrated the presence of 5-HT in the brain. 
There is considerable variation in the amount of 5-HT present in various parts of the brain. High concentrations of 5-HT are present in the hypothalamus, amygdala and brain stem.

In the medulla and pons, $4 \%$ of the neurons are excited and $49 \%$ are inhibited by 5-HT. In other regions of the brain, the effect of 5-HT on single neurons has been found to be inhibitory (Curtis \& Davis, 1962).

Oral administration of lysergic acid diethyl amide (LSD), a 5-HT antagonist in isolated tissues, produces a pronounced psychic disturbance in human beings. Similar effects are seen with several other 5-HT antagonists like medmain, yohimbine, harmala alkaloids, etc. (Wooley \& Shaw, 1954). However, not all antagonists of 5-HT produce psychotic symptoms, 2-bromolysergic acid diethylamide (BOL) being an important exception in this regard. The extracts of mice brain treated with BOL have been shown to possess an anti-5-HT action (Cerletti \& Rothlin, 1955), although it was initially argued that BOL does not penetrate into the central nervous system. Reserpine, which depletes the brain of 5-HT, has been used as a tranquillizer and it has been suggested that 5-HT may function in the brain as a neurohumoral transmitter (Brodie, Fletscher \& Shore, 1955). The original hypothesis of Hess has been revived and it has been postulated that in the brain there are two opposing types of systems for coordination of the somatomotor activity. One is called 'ergotrophic' which is activated by noradrenaline and leads to excitement and increased sympathetic activity, whereas the 'trophotropic' system is subserved by 5-HT, predominance of which causes parasympathetic stimulation and apathy (Brodie, Prockop \& Shore, 1958).

This is an interesting example of the action of drugs in modifying the physiological actions of mediators. With modern techniques, further observations along these lines are expected.

\section{Amino acids}

The glutamate ion is a general excitant and $\gamma$-amino butyric acid (GABA) is an inhibitory agent to the neurons of the CNS. These two substances are present in the brain and are effective even in low concentration. GABA is formed from glutamate by a process of decarboxylation. Jasper, Khan \& Elliott (1965) have shown that in experimental animals the turnover of GABA was about three times more rapid when a sleep pattern of EEG was maintained, whereas in a continuous waking state no measurable GABA could be obtained in the perfusate. The roles of glutamate and GABA in the trans- port, metabolism and function of the neurons are closely interrelated and it has been suggested (Gaddum, 1965) that both compete for the same receptors although they have opposing actions. The exact nature of these has yet to be elucidated.

\section{Polypeptides}

Substance $\mathbf{P}$ is a polypeptide with remarkable pharmacological properties and it has a specific distribution in the extracts of brain (Lembeck \& Zetter, 1962).

In cats, substance $P$ leads to an impression of deep sedation on intraventricular administration. Similar results have been obtained in mice (Capek, 1963). However, the physiological functions of substance $\mathbf{P}$ in the brain have not been clearly demarcated.

\section{Ergothionine}

Crossland (1960) and Crossland \& Mitchell (1958) investigated the actions of cerebellar extracts on cerebellar neurons and demonstrated powerful excitatory actions. This cerebellar excitatory factor has now been identified as ergothionine, a betaine of thiolhistidine (Crossland, Woodruff \& Mitchell, 1964).

\section{Histamine}

The distribution of histamine in different areas of the brain has been mapped in some detaib (Adam, 1961). The histamine content of the pitu? itary gland and hypophyseal stalk is related to their mast cell content. Brain tissue proper does not contain mast cells. Adam \& Hye (1964) observed that compound 48/80 lowered the histamine content of the pituitary gland and the hypophyseal stalk (i.e. mast-cell containing tissues), but not that of the thalamus and hypothalamus. In the latter sites, reserpine lowered the histamine content without affecting it in the former. In the brain both the synthesizing enzyme histidine decarboxylase and the catabolizing enzyme imidazole-N-methyl transferase are present. Methylation seems to be the principal pathway for the inactivation of histamine in the brain.

Electrophoretic administration of histamine in the CNS leads to inhibition of the neuronal activity in the cerebral cortex (Krnjevic \& Phillis, 1963b). Furthermore, histamine has been shown to possess a regulatory action on the pituitaryadrenocortical system (Suzuki et al., 1963).

\section{Inorganic ions}

Inorganic ions are also likely to be of importance in the CNS. Potassium ions have been shown to cause mild excitation. Some chemical mediators act directly by interfering with ionic 
imbalance presumably by altering the permeability of the cell membrane.

The physiology of the central nervous system is thus at present being rewritten. This in its turn will lead to revision of our ideas about drug action on the central nervous system, and it is hoped that it may become possible to define the actions of drugs such as analgesics, hypnotics and tranquillizers in terms of specific transmitter release as is now possible for a number of substances acting on the peripheral nervous system.

\section{References}

AdAM, H.M. (1961) Regional Neurochemistry. Pergamon Press, Oxford.

ADAM, H.M. \& HYE, H.K.A. (1964) Effect of drugs on the concentration of histamine in the hypophysis and proximate parts of the brain. J. Physiol. (Lond.), 171, 37P.

Amin, A.H., Crawford, T.B.B. \& Gaddum, J.H. (1954) The distribution of substance-P and 5-hydroxytryptamine in the central nervous system of the dog. J. Physiol. (Lond.), 126, 596.

Bradley, P.B., Dhawan, B.N. \& Wolstencroft, J.H. (1964) Some pharmacological properties of chotinoceptive neurones in the medulla and pons of the cat. J. Physiol. (Lond.), 170, 59P.

Bradley, P.B. \& Wolstencroft, J.H. (1965) Actions of drugs on single neurones in the brain stem. Brit. med. Bull. 21, 15.

Brodie, B.B., Fletscher, A. \& Shore, P.A. (1955) Evidence that serotonin has a role in brain function. Science, 122, 968.

Brodie, B.B., Prockop, D.J. \& Shore, P.A. (1958) An interpretation of the action of psychotropic drugs. Postgrad. Med. 24, 296.

BUlbring, E. \& BURN, J.H. (1941) Observations bearing on synaptic transmission by acetylcholine in the spinal cord. J. Physiol. (Lond.), 100, 337.

BURN, J.H. (1965) Current concepts about adrenergic transmission. J. med. Sci. $2,3$.

CAPEK, R. (1963) Some effects of bradykinin on the central nervous system. 1st Int. Pharmacol. Meeting, 9, 61.

Carlesson, A., Falck, B., FuXe, K. \& HillarP, N.A. (1964) Cellular localisation of the monoamines in the spinal cord. Acta physiol. scand. 60, 112.

Carlsson, A., Falck, B. \& Hillarp, N.A. (1962) Cellular localisation of brain monoamines. Acta physiol. scand. 56, Suppl. 196, 1.

Cerletti, A. \& Rothlin, E. (1955) Role of 5-hydroxytryptamine in mental disease and its antagonism to lysergic acid derivatives. Nature (Lond.), 176, 785.

Crossland, J. \& Mitchell, J.F. (1958) The effect on the electrical activity of the cerebellum of a substance present in cerebellar extracts. J. Physiol. (Lond.), 132, 391.

Crossland, J., Woodruff, G.N. \& Mitchell, J.F. (1964) Identity of the cerebellar factor. Nature (Lond.), 203, 1388.

Curtis, D.R. (1961) Nervous Inhibition. Pergamon Press, Oxford.

Curtis, H.R. (1965) Actions of drugs on single neurones in the spinal cord and thalamus. Brit. med. Bull. $21,5$.

Curtis, D.R. \& Davis, R. (1962) Pharmacological studies upon neurones of the lateral geniculate nucleus of the cat. Brit. J. Pharmacol. 18, 217.

CurTis, D.R. \& ECCles, R.M. (1958) The excitation of Renshaw cells by pharmacological agents applied electrophoretically. J. Physiol. (Lond.), 141, 435.
Curtis, D.R. \& Kolzumi, K. (1961) Chemical transmitter substances in the brain stem of cat. J. Neurophysiol. $24,80$.

Curtis, D.R., Phillis, J.W. \& Watkins, J.C. (1961) Cholinergic and noncholinergic transmission in the mammalian spinal cord. J. Physiol. (Lond.), 158, 296.

CURTIS, D.R. \& RYAll, R.W. (1964) Nicotinic and muscarinic receptors of Renshaw cells. Nature (Lond.), 203, 652.

Dale, H.H., Feldberg, W. \& Vogt, M. (1936) Release of acetylcholine at voluntary motor nerve endings. J. Physiol. (Lond.), 86, 353.

DE Robertis, E. (1964) Biogenic amines. Progr. Brain Res. 8, 145.

EllotT, T.R. (1904) On the innervation of the ileocolic sphincter. J. Physiol. (Lond.), 31, 157.

FeldberG, W. \& KraYer, O. (1933) Das Aufrreten eines azetylcholinartigen Stoffes in Herzvenenblut von Warmblütern bei Reszung der Nervi vagi. Arch. exp. Path. Pharmak. 172, 170.

FeldberG, W. \& SHERwood, S.L. (1954) Injections of drugs into the lateral ventricle of the cat. J. Physiol. (Lond.), $123,148$.

GADDUM, J.H. (1961) Substances released in nervous activity (Abstract). Biochem. Pharmacol. 8, 81.

Gaddum, J. H. (1962) Proc. 1st Int. Pharmacol. Meeting, 8, 1.

GADDUM, J.H. (1965) Pharmacology of the central nervous system. Brit. med. Bull. $21,1$.

JASPER, H.H., KhAN, R.T. \& ElliotT, K.A.C. (1965) Aminoacids released from the cerebral cortex in relation to its state of activation. Science, 147, 1448.

KRnjević, K. \& Phillis, J.W. (1963a) Iontophoretic studies of neurones in the mammalian cerebral cortex. J. Physiol. (Lond.), 165, 274.

Krnjević, K. \& Phillis, J.W. (1963b) Actions of certain amines on cerebral cortical neurones. Brit. J. Pharmacol. 20,471 .

LEMBECK, F. \& ZETTER, G. (1962) Substance P: a polypeptide of possible physiological significance, especially within the nervous system. Int. Rev. Neurobiol. 4, 159.

LOEWIE, O. (1921) Über humorale übertragbarkeit der herznerwirkung. Pflüg. Arch. ges. Physiol. 189, 239.

Macintosh, F.C. \& OboRin, P.E. (1953) Abstr. XIX Int. Physiol. Congress, 380.

McCance, I. \& Phillis, J.W. (1964) The action of acetylcholine on cells in cat cerebellar cortex. Experientia, 20, 217.

McLennan, H. (1963) Synaptic Transmission. Saunders, Philadelphia.

Mitchell, J.F. (1963) The spontaneous and evoked release of acetylcholine from the cerebral cortex. J. Physiol. (Lond.), 165, 98.

Oliver, G. \& Schafer, E.A. (1895) The physiological effects of extracts of the suprarenal capsules. J. Physiol. (Lond.), 18, 230.

Paton, W.D.B. (1958) Central and synaptic transmission in the nervous system (pharmacological aspects). Ann. Rev. Physiol. 20, 431.

Phillis, J.W. (1965) Cholinergic mechanisms in the cerebellum. Brit. med. Bull. 21, 26.

Robson, J.M. \& StaceY, R.S. (1962) Pharmacologically active substances in the central nervous system. Recent Advanc. Pharmacol. 3, 1.

Salmoiraghi, G.C., Costa, E. \& Bloom, F.E. (1965) Pharmacology of central synapses. Ann. Rev. Pharmacol. 5, 213.

SANDBorn, E. (1964) Cytoplasmic microtubules in the neurone (Abstract). Anat. Rec. 148, 330.

SHerwood, S.L. \& FeldberG, W. (1953) A permanent cannula for intraventricular injections in cats. J. Physiol. (Lond.), 120, 3P.

SPEHLMAN, R. (1963) Acetylcholine and prostigmine electrophoresis at visual cortex neurones. J. Neurophysiol. 26, 127. 
Suzuki, T., Hirai, K., Yoshio, H., Kurouji, K. \& YamaSHITA, K. (1963) Effect of histamine on adrenal 17hydroxycorticoid secretion in unanaesthetised dogs. Amer. J. Physiol. 204, 847.

SzERB, J.C. (1963) Nature of acetylcholine like activity released from brain in vivo. Nature (Lond.), 197, 1016.

VoGT, M. (1954) The concentration of sympathin in different parts of the central nervous system under normal conditions and after the administration of drugs. J. Physiol. (Lond.), 123,451 .
WhitTAKeR, V.P. (1959) The isolation and characterization of acetylcholine containing particles from brain. Bioche $m$. J. 72, 694.

Whittaker, V.P., Michaelson, I.A. \& Kirkland, R.J.A. (1964) The separation of synaptic vesicles from nerveendings, particles (synaptosomes). Biochem. J. 90, 293.

Wooley, D.W. \& SHAw, E. (1954) Some neurophysiological aspects of serotonin. Brit. med. J. ii, 122. 